\title{
Individual's Communicative Abilities in the Conditions of Virtual Environment
}

\author{
Maria Kunyaeva \\ Philosophy Department \\ Bauman Moscow State Technical University \\ 5, 2-ya Baumanskaya Street \\ Moscow, Russian Federation 105005 \\ E-mail: maria_kunyaeva@bmstu.ru
}

\begin{abstract}
The following article describes the problem of globalization processes influence on the linguistic identity's activity under the conditions of information society formation in the discourse of utilizing information and communication technologies. Authors have noted the need to develop communication activity and professional culture relating to the virtual environment. Today the individual should continuously update relevant information employing information and communication technologies to conform to modern conditions. It is necessary that the corresponding conditions be created to retain information and knowledge of participants and coherence with the available communication network. In these circumstances, interaction between them and the advanced information and communication technologies competent application can ensure proper virtual environment acquisition.
\end{abstract}

Keywords-information and communication technologies; virtual environment; features of globalization processes; linguistic identity; communication activity; communicative ability; intercultural communication

\section{INTRODUCTION}

Modern social-philosophical literature pays much attention to the features of society, the particular linguistic identity, and also interpersonal communicative processes [1] [2] [3] [4]. They are considered to be significant social change factors during the era of globalization and information revolution [5]. The role of language becomes more and more noticeable. The modern world brings in new identity forms. Furthermore, the rapid development of communication activity together with the Internet significantly changes social communication activity, creates new problems and induces on the search for the solutions.

Many research works on the globalization describe an entirely new social community of people which becomes uncuttable from the concept of "globalization" [6] [7] [8]. For these people, such chaos becomes the nature of permanence. However, thanks to the principle of integrity we may perceive, for example, the development of thinking which base is the worldview outlook formation and the new system of concepts. This process depends on the ability to work with information as the most critical element of general cultural competences in modern conditions.

So, the central transformation character from the traditional paradigm became a sharp, high-quality shift from one way of information storage, broadcasting and processing, and also methods of its representation to the other. Term "information leap" clearly explains such conversion [9]. Besides, the transition noted above was also influenced by the development of the information and communication or virtual environment, in particular, the Internet [10]. The extensive use of information and communication technologies also influences interactions during individuals' activity.

Today the Internet represents a global communication network which gives the chance to distribute data, information, and knowledge more efficiently. This aspect serves as one of the main reasons for the communicative processes transformation. The appropriate language means and forms of individuals in modern conditions are the basis for their communicative processes. Those described above and also other factors specified in work have generated the new society defined as the "network society" [11]. Other papers formulate it as a global intellectual and telecommunication society [12]

The problem regarding the investigation of globalization influence in the conditions of the network society formation and its influence on discourse within the individual's activity at the present stage through the application of information and communication technologies is of particular importance. Our study will define the primary objective of research, namely, consider the globalization processes features influence on communication activity.

\section{RELEVANT FEATURES OF GLOBALIZATION AND THEIR INFLUENCE ON THE INDIVIDUAL'S ACTIVITY IN MODERN CONDITIONS}

The transformation processes to the globalization 3.0, the revolution in mass communication and also transition to post-industrial society have begun thanks to the development of information and communication technologies [13]. The J.A. Johannessen's and B. Olsen's paper identifies these 
processes as the free flow (distribution) of information, knowledge, and technologies through space and time which is an exceptional feature of the globalization [14]. So, it is required to address to the system of knowledge formation in a new way that influences communication activity.

Relevant consideration of information, for example, about global tendencies, is especially crucial and significant for the person concerning due existence in present-day society. Individuals carry out the understanding (absorption) of "what occurs around" thanks to the available and free transfer of information and knowledge in the virtual environment using advanced information and communication technologies. For example, it can become a contradictions identification which arises because of information turbulence [15]. Such turbulence may occur while studying the virtual environment caused by the noted above dynamics of their activity processes in modern conditions.

Therefore, individuals should well-timed monitor and correct knowledge for the achievement of objectives within the virtual environment through information and communication technologies. For example, we may apply it to students who master the particular discipline. Such activity can contribute to the development of their flexibility through an adequate perception of the information and communication environment. Mentioned conditions are necessary for expanding the intellectual horizons, destroying false knowledge and carrying out communication activity.

It is necessary that the individual, who master within the virtual environment through the latest information and communication technologies, should appropriately use, create and distribute, non-material resources to predict possible changes. It is essential for them to make proper decisions, predictions and the corresponding operations under the information and communication environment, and also to compare them with the current surrounding situation. Therefore, today it is vital for the modern person to create information and communication flows. As a confirmation, it is suitable to refer to the work in which M. Castells states that "electronic communication networks will produce a basis for our life" [16].

\section{TRANSITION OF THE MODERN HUMAN FROM TRADITIONAL VALUES}

Processes of globalization force the man of today to transform from the traditional values inherent in the previous stage and adapt communication activity toward the new time. For example, M. McLuhan's work divides the development of civilization into three stages: preliterate culture with oral forms of communication; written culture; present stage of information communications [17]. On the contrary, another work allocates the following steps: an invention of writing; an invention of book-printing; an invention of the telephone, the radio, and the television [18].

As today human activity is carried out at the global scale, adaptation consists of the value creation in the development of the information and communication environment considering the use of the advanced information and communication technologies. Such environment can demand, for example, entirely new forms (structures) of communication activity for their beneficial adaptation. This process of adaptation in new conditions in many respects depends today on the efficient use of non-material resources using the advanced information and communication technologies within the information and communication environment.

Therefore, all this can lead to the corresponding development of the communication activity of the particular individual or a group. Such development assumes the presence of:

- Firstly, the corresponding conditions for accumulating information and knowledge of participants' intercommunications in the information and communication environment;

- Secondly, coherence with an already available communication network in the information and communication environment for ensuring proper and precise interactions between them;

- Finally, the corresponding conditions of the advanced information and communication technologies competent application for the sufficient development of the information and communication environment.

All before-mentioned is necessary for handling the information' transformation dynamics in individuals' interactions within information and communication environment. For example, it is relevant for the communication activity development at all the educational levels and stages.

Thus, individuals should systematize both the intellectual and creative potential and knowledge in the participants' intercommunications within the information and communication environment. It is significant that the presence of the developed socio-technical information system should keep and even increase the knowledge, which will be able to help certain individuals to get to the new level of communication activity. It will help them to consider their needs. The educational organization providing students or listeners with the new knowledge using information and communication system could serve as an example. Also, it can help to do the following:

- to reduce the excess of information or its undesirable duplication and adjustment that can distort the knowledge value;

- to hasten decision-making process toward the communication activity which can decrease time expenditure [19];

- to reveal new ways for the improvement of the communication activity process in the virtual environment.

Another globalization feature called free migration of people and groups can influence their communication activity [20]. It is possible to characterize this globalization 
feature as the demographic force free flow positively influences general cultural development.

The above-cited sources generally state that this feature of globalization serves as the active tool for people and groups concerning the almost free crossing of geographical boundaries. However, they do not consider the influence of the virtual environment development dynamics. There are changes in many human managing spheres. It is so due to the increasing use of the advanced information and communication technologies by individuals and also due to the information and communication environment development. That leads to changes in their traditional communication activity within modern conditions.

In works M. Castells has considered many challenging issues of modern era information and communication processes which continue to transform the present environment and also influence the communication activity of the linguistic identity [21] [22] [23]. Therefore, more and more people participate in a global communication activity that brings up questions of information and communication technologies competent use within the information and communication environment. It forces him to adapt and be more updated, for example, to respectively perceive remote interactions using the Internet for beneficial communicative processes - intercommunications which do not depend on time and area limits.

Current operational feedback is a new standard and the communication activity, formed using modern information and communication technologies, can provide the linguistic identity's development thanks to the fast information transfer [24]. This information transfer can allow the particular individual to expand the opportunities on a global scale of the modern environment.

The communication activity development can support further growth of the particular individual or a group twenty four-seven through new knowledge and competence thanks to globalization processes. Therefore, an available competence in operating within virtual environment serves as an exceptional value for the present-day man or a group of participants regarding intercommunications. Another important aspect is a degree of relationships development and their integration into the external ideas during the communication activity process.

Given these facts and data, we can conclude that there is a real opportunity to specify numerous communication activity processes' improvement ways and to adapt to today's conditions of the virtual environment using the considered approach which has the network attribute.

New society suggests the person's communication activity adjustment in respect to global communications. It involves the development of the linguistic identity. What is more, it is necessary to continuously update relevant information concerning new conditions in the information and communication environment through information and communication technologies. Knowledge about the communication activity's abilities and behavior in current situation can serve as a component of the linguistic identity development. In this regard, present-day individuals need to know and compare the communicative abilities with tendencies to expand new boundaries.

It is evident that the transition from the previous period (globalizations 2.0) happened thanks to the technological progress and considerable social changes in the newly established network society. According to some works, these changes became the reason for the new virtual environment development that has led to the cross-cultural interaction which is believed to be another unique globalization feature [25]. It has caused the development of such entirely new phenomena in the communication activity culture. We are referring here to the linguistic identity's activity phenomena. Now the individuals and groups which are operating in a modern virtual environment should consider it and adequately develop the corresponding competence. The question here is not only about such competence as the communication activity's professional culture, but also about the communication culture with the use of modern information and communication technologies in the conditions of human-computer interaction using computational (computer) linguistics.

Therefore, the multicultural base of network community allows individuals to resolve arising problems, analyzing such different aspects as:

- Firstly, we can reach it by establishing communication activity using modern information and communication technologies by the competent representatives from various spheres of activity. They are concentrated within the network and can share the available experience and knowledge, for example, in questions of various regions' intercommunication;

- Secondly, it does not depend on a geographical location and time in virtue of modern information and communication technologies.

As we mentioned before, it is essential that particular individuals and groups should obtain special competence in the information and communication environment acquisition through information and communication technologies and the access to the global Internet. Thereby they have a possibility of the proxy interaction for a successful way out practically from any situation remotely through the direct online communication activity. Thanks to the remote exchange of information and knowledge between people in global world space, it is possible to gain the necessary experience for their due extensive functioning.

Therefore, it is possible for the individual to develop communication activity and professional culture in virtue of the acquired through information and communication technologies corresponding knowledge and its systematization. In current terms, an individual requires competence to interact and function successfully using information and communication technologies. It is important to note that modern society puts non-material resources in the forefront. Knowledge became a strategically valuable source. The S. C. Lenny Koh's and S. Maguire's study focuses on the fact that initiative in the field of information 
and communication technologies will not necessarily be successful, yet there is a high probability for various problems and mistakes to emerge [26].

\section{CONCLUSION}

Given these facts and the data, we will note the importance of formation individuals' adequate competence while employing virtual environment through the corresponding information and communication technologies for the proper development of language activity. It assumes the relevant communication networks creation for ensuring proper interaction between people during communication activity which is reached practically through the selfimprovement and self-development in the virtual environment.

Today each person has to use latest tools and methods to avoid detrimental effect fronting interactions during the new communication activity. Advanced information and communication technologies have to become a particular basis for these tools so that individual could use them for the communicative and perceptual behavior in modern conditions

The present-day person, mastering the virtual environment through information and communication technologies and the global Internet, uses knowledge as a product that influences his communication activity in the global conditions. Therefore, information and communication technologies are the critical competence of ensuring efficient linguistic identity's communication activity regarding the modern environment. This should be the subject of further research.

\section{REFERENCES}

[1] B. A. Rodionov, "Communication as a Social Phenomenon", Rostovon-Don: Published by Rostov University, 1984, pp. 143.

[2] G. G. Pocheptsov, "Communicative Technologies of the Twentieth Century”, Moscow: Refl-book Publ., Kiev: Vakler Publ., 2000, pp. 351

[3] V. P. Konetskaya, "Sociology of Communication", Moscow: International University of Business and Management, 1997, pp. 304.

[4] V. A. Kanke, "Philosophy: Textbook for High and Specialized Secondary Schools”, Moscow: Logos, 2001, pp. 272.

[5] V. Y. Ivlev, M. L. Ivleva, V. A. Inozemtsev, "Formation of a New Philosophico-Methdological Paradigm of Modern Science in the Information Society", Moscow: OOO "ITO SEMRIK", 2012, pp. 132.

[6] M. Castells, "End of Millennium. The Information Age: Economy, Society and Culture Volume III", Paperback, 2nd Edition, Vol 3, Published by Wiley-Blackwell, 2000, pp. 448.

[7] M. Castells, "The Internet Galaxy: Reflections on the Internet, Business, and Society", Oxford University Press, 2001, pp. 304.

[8] M. Castells, "The power of Identity", 2nd Edition, Published by John Wiley \& Sons, 2011, pp. 584.

[9] V. Y. Ivlev, M. L. Ivleva, V. A. Inozemtsev, "Formation of a New Philosophico-Methdological Paradigm of Modern Science in the Information Society". P. 18.

[10] J.-A. Johannessen, B. Olsen, "The Future of Value Creation and Innovations: Aspects of a Theory of Value Creation and Innovation in a Global Knowledge Economy", International Journal of Information Management, vol. 30, 2010, pp. 502-511.
[11] M. Castells, "End of Millennium. The Information Age: Economy, Society and Culture Volume III".

[12] V. Y. Ivlev, M. L. Ivleva, V. A. Inozemtsev, "Formation of a New Philosophico-Methdological Paradigm of Modern Science in the Information Society". P. 4

[13] J. Valacich, C. Schneider, "Information Systems Today Managing in the Digital World", 6th Edition, Pearson, 2013, pp. 576.

[14] J.-A. Johannessen, B. Olsen, "The Future of Value Creation and Innovations: Aspects of a Theory of Value Creation and Innovation in a Global Knowledge Economy”. P. 510.

[15] M. Castells, "The Internet Galaxy: Reflections on the Internet, Business, and Society". P. 106

[16] M. Castells, "End of Millennium. The Information Age: Economy, Society and Culture Volume III". P. 389.

[17] M. McLuhan, "The Gutenberg Galaxy: The Making of Typographic Man” Transl. I. O. Tyurina, 2nd Edition, Moscow: Academic Project Gaudeamus, 2013, pp. 496.

[18] V. Y. Ivlev, M. L. Ivleva, V. A. Inozemtsev, "Formation of a New Philosophico-Methdological Paradigm of Modern Science in the Information Society". P. 19.

[19] M. McLuhan, "At the Moment of Sputnik the Planet Becomes a Global Theatre in which There Are No Spectators but Only Actors", Journal of Communication, Winter, 1974, pp. 48-58.

[20] J. Valacich, C. Schneider, "Information Systems Today Managing in the Digital World". P. 12.

[21] M. Castells, "End of Millennium. The Information Age: Economy, Society and Culture Volume III", Paperback, 2nd Edition, Vol 3 , Published by Wiley-Blackwell, 2000, pp. 448.

[22] M. Castells, "The Internet Galaxy: Reflections on the Internet, Business, and Society", Oxford University Press, 2001, pp. 304

[23] M. Castells, "The power of Identity", 2nd Edition, Published by John Wiley \& Sons, 2011, pp. 584

[24] J.-A. Johannessen, B. Olsen, "The Future of Value Creation and Innovations: Aspects of a Theory of Value Creation and Innovation in a Global Knowledge Economy". P. 504.

[25] M. Castells, "The power of Identity". P. 2

[26] S. C. Lenny Koh, S. Maguire, "Information and Communication Technologies Management in Turbulent Business Environments", Hershey, PA, 2009, pp. 423. 